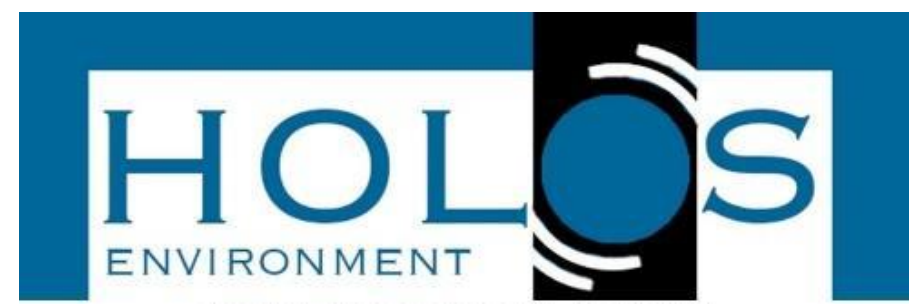

\title{
AVALIAÇÃO DA QUALIDADE DAS ÁGUAS SUPERFICIAIS E DO SISTEMA DE TRATAMENTO DO ESGOTO SANITÁRIO DO MUNICÍPIO DE RIO CLARO/SP
}

\section{ASSESSMENT OF THE QUALITY OF SURFACE WATERS AND THE SEWAGE TREATMENT SYSTEM IN THE CITY OF RIO CLARO / SP}

\author{
Renata Xavier Lona de Moraes ${ }^{1}$; Lauren Nozomi Marques Yabuki ${ }^{1}$; \\ João Gabriel Thomaz Queluz ; Marcelo Loureiro Garcia ${ }^{1}$
}

Artigo recebido em: 26/08/2020 e aceito para publicação em: 12/10/2020.

DOI: http:/dx.doi.org/10.14295/holos.v21i1.12421

\begin{abstract}
Resumo: A manutenção da qualidade da água é fundamental, tendo em vista que somente uma parcela reduzida do seu volume total está disponível para utilização direta. O lançamento de efluentes fora dos padrões de qualidade pode agravar significativamente esse cenário. O gerenciamento correto de águas residuárias torna-se ainda mais importante em períodos de crise hídrica, para a qual uma solução é o reuso por meio de tratamento avançado. Assim, foi objetivo deste trabalho avaliar o padrão de qualidade de águas do município de Rio Claro (SP). Ao longo dos rios Corumbataí e Ribeirão Claro, cinco pontos foram analisados em relação a diversos parâmetros de qualidade de águas, em trechos que abrangiam tanto a montante de pontos de captação de água, quanto a jusante de lançamento de esgotos tratados. Os resultados obtidos foram comparados às legislações vigentes sobre os temas, para averiguar a conformidade com os padrões estabelecidos. O Índice de Qualidade das Águas foi apresentado com a classificação boa em praticamente todos os pontos, exceto o ponto mais a jusante do município que obteve a classificação regular. As concentrações de alumínio dissolvido e ferro dissolvido apresentaram-se acima dos limites estabelecidos pela legislação no ano de 2018 em todos os pontos, especialmente no período chuvoso. Nos períodos de 2010-2014 e 2013-2017: os valores de Escherichia coli ultrapassaram os limites legais também para todas as localizações, com os piores resultados para os dois pontos a jusante; os valores mais elevados para condutividade elétrica, demanda bioquímica de oxigênio e fósforo total foram obtidos nos dois pontos a jusante, acima dos limites. Para os dados referentes ao sistema de tratamento de esgoto do município, foram demonstradas elevadas eficiências na remoção de matéria orgânica.
\end{abstract}

Palavras-chave: Qualidade de águas superficiais. Município de Rio Claro/SP. Estação de Tratamento de Esgoto

\begin{abstract}
The preservation of the water quality is essential, considering that only a reduced portion of its total volume is available for direct use. The release of effluents beyond water quality standards can significantly aggravate this scenario. The correct management of wastewater becomes even more important in periods of water crisis, for which a solution is reuse through advanced treatment. Thus, the objective of this work was to evaluate the water quality standard in the city of Rio Claro (SP). Along the rivers Corumbataí and Ribeirão Claro, five sampling points were analyzed in relation to several water quality parameters, including both upstream areas of water catchment and downstream areas of treated sewage discharges. The results were compared to the current environmental legislation to ascertain compliance with the established standards. The Water Quality Index (WQI) presented the classification good for all sites, except the downstream one that received the classification regular. . Dissolved aluminum and iron concentrations were above legal limits in 2018, at all locations, especially in the rain
\end{abstract}

${ }^{1}$ Universidade Estadual Paulista (UNESP), Instituto de Geociências e Ciências Exatas (IGCE), São Paulo, SP. E-mails: renatalona@hotmail.com, lauren.yabuki@unesp.br, igtqueluz@gmail.com, marcelo.garcia@unesp.br 
season. In the periods of 2010-2014 and 2013-201: Escherichia coli values were above limit also at all locations, with the worst data for the two sites further downstream; the highest values for total phosphorus, electrical conductivity and biochemical oxygen demand were obtained to the two locations further downstream as well, exceeding legal limits. High organic matter removal efficiencies were reported for two wastewater treatment plants in Rio Claro.

Keywords: Quality of Surface Water. City of Rio Claro/SP. Sewage Treatment Plant.

\section{INTRODUÇÃO}

A água é um recurso vital para a manutenção da vida no planeta, podendo ser usada e reutilizada para diversos fins, dependendo de suas características e prérequisitos para tal propósito: abastecimento humano e industrial, irrigação, lazer, entre outros. Segundo dados do Plano Nacional de Recursos Hídricos (2006), aproximadamente $70 \%$ da superfície de nosso planeta é ocupada por água, porém $97,5 \%$ da água do planeta é salgada. Da parcela restante de água doce (2,5\%), 68,9\% encontra-se em locais de difícil acesso (geleiras, calotas polares ou em regiões montanhosas), 29,9\% em águas subterrâneas, 0,9\% compõe a umidade do solo e dos pântanos e apenas $0,3 \%$ constitui a porção superficial de água doce presente em rios e lagos. . Por ser um recurso tão escasso, a manutenção de sua qualidade é imprescindível.

O lançamento de efluentes, urbanos e industriais sem tratamento algum ou sua disposição de forma inadequada nos corpos d'água é motivo de grande preocupação, pois coloca em risco a saúde e bem-estar da população (VON SPERLING, 2005). Esse lançamento inadequado afeta também todo o ecossistema aquático ocasionando desequilíbrios, já que esses efluentes aumentam a concentração de matéria orgânica nos corpos d'água, e diminuem os níveis de oxigênio dissolvido (MOTA, 2008). Nesse âmbito, a Lei o 11.445 de 2007, que estabelece a Política Nacional de Saneamento Básico, define saneamento básico como sendo o conjunto de serviços, infraestruturas e instalações operacionais relacionadas aos sistemas de abastecimento de água, esgotamento sanitário, limpeza urbana e manejo de resíduos sólidos e drenagem e manejo das águas pluviais urbanas (BRASIL, 2007).

De acordo com dados do ano de 2018, apresentados pelo Sistema Nacional de Informações sobre Saneamento (SNIS), $83,6 \%$ da população brasileira possui atendimento com rede de abastecimento de água e somente $53,2 \%$ é atendida com redes de coleta de esgoto. Sendo que, do total coletado, $25,4 \%$ não possui nenhuma 
forma de tratamento, além dos $46,8 \%$ que são gerados e que não possuem sistema de coleta (BRASIL, 2018). Essa lacuna no atendimento de sistema de saneamento acaba causando os problemas de lançamento de efluentes sem tratamento e, consequentemente, afetando a qualidade dos corpos hídricos.

Nesse contexto, são utilizados diversos parâmetros para avaliar a qualidade das águas superficiais como cor, turbidez, condutividade, temperatura, $\mathrm{pH}$, alcalinidade, dureza, oxigênio dissolvido, demanda bioquímica de oxigênio, demanda química de oxigênio, metais pesados, entre outros. Sendo assim, monitorar esses parâmetros é essencial para garantir os valores recomendados pela legislação vigente. No Brasil, o Conselho Nacional do Meio Ambiente (CONAMA) através da Resolução 357/2005, complementada pela Resolução 430/2011, estabelece os padrões de lançamento de efluentes e determina critérios ambientais para o enquadramento dos corpos d'água superficiais. Essa resolução classifica as águas em 13 classes, sendo 5 classes de água doce, considerando seus usos preponderantes atuais e futuros (BRASIL, 2005).

No Estado de São Paulo, a Companhia Ambiental do Estado de São Paulo (CETESB) é o órgão ambiental que monitora a qualidade das águas superficiais. $O$ órgão responsável por regular e fiscalizar os serviços de saneamento básico do município objeto de estudo deste trabalho (Rio Claro), é a Agência Reguladora dos Serviços de Saneamento das Bacias dos Rios Piracicaba, Capivari e Jundiaí (ARESPCJ)

Diante do contexto apresentado acima, este trabalho teve como objetivo principal, a análise da qualidade das águas superficiais e do desempenho do sistema de tratamento do esgoto sanitário do município de Rio Claro (SP), abrangendo os anos de 2010 a 2018.

\section{MATERIAL E MÉTODOS}

\section{1 Área de Estudo}

O município de Rio Claro se localiza no interior do Estado de São Paulo e pertence à Unidade de Gerenciamento de Recursos Hídricos 05 (UGRHI - 05), constituída pelos rios Piracicaba, Capivari e Jundiaí, bacias afluentes do rio Tietê (Figura 1) e a maior parte de sua área pertence à sub-bacia do rio Corumbataí. $\mathrm{A}$ 
população estimada do município no ano de 2019, de acordo com dados do Instituto Brasileiro de Geografia e Estatística (IBGE), era de 206.424 habitantes (IBGE, 2019).

Figura 1 - Unidade de Gerenciamento de Recursos Hídricos 05

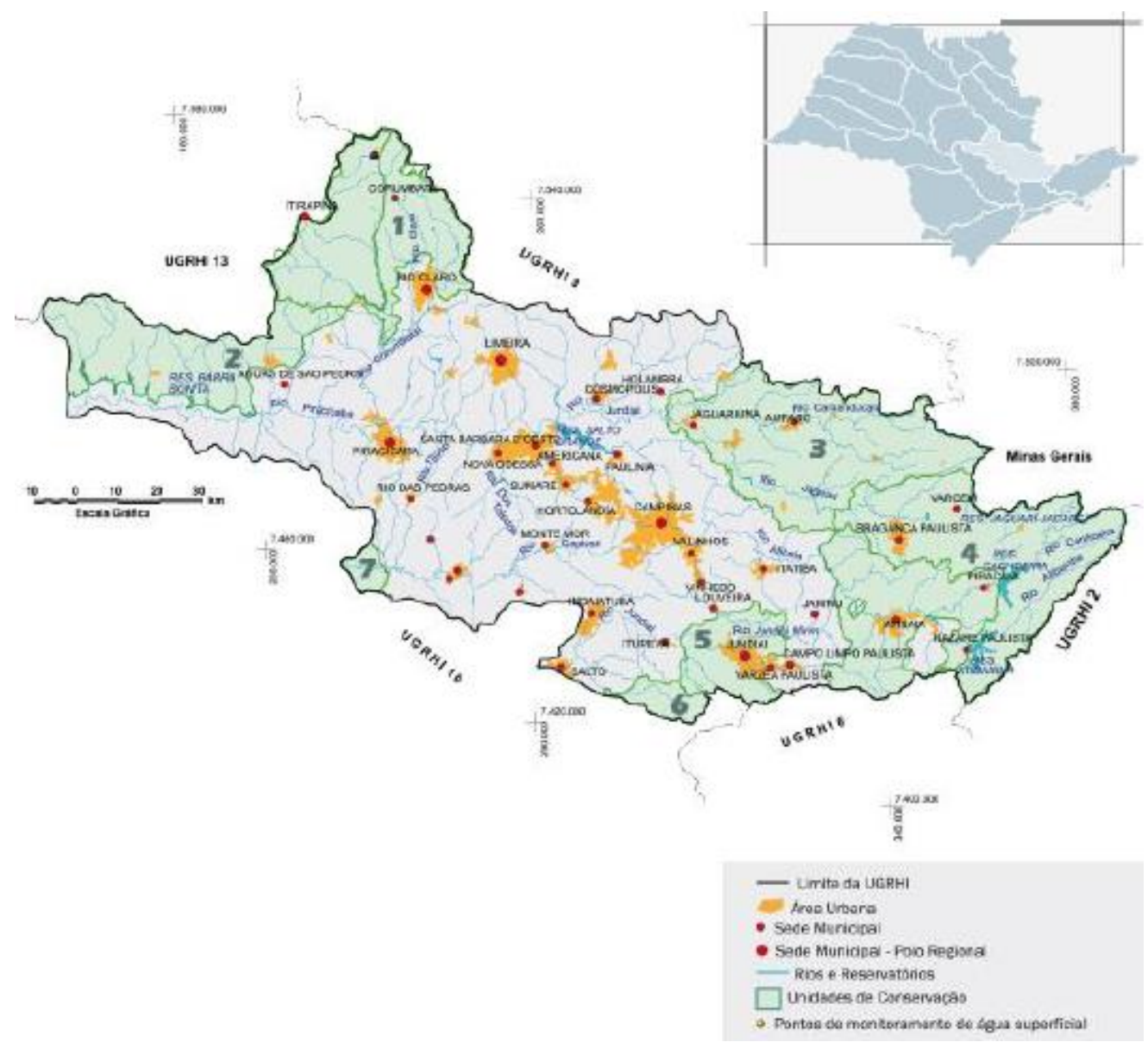

Fonte: Sistema Integrado de Gerenciamento de Recursos Hídricos do Estado de São Paulo (2019).

A Bacia Hidrográfica do Rio Corumbataí apresenta aproximadamente 1710 km² e é dividida nas sub-bacias Alto Corumbataí, Passa-Cinco, Médio Corumbataí, Ribeirão Claro e Baixo Corumbataí (VALENTE e VETTORAZZI, 2005). Com população estimada em cerca de 710 mil habitantes, segundo dados do IBGE (2018), a bacia tem grande importância socioeconômica pois possui um potencial hídrico capaz de abastecer as cidades de Analândia, Corumbataí, Rio Claro, Santa Gertrudes, Ipeúna, Itirapina e Charqueada e, além disso, permite a exportação de água para municípios localizados em bacias vizinhas, como Araras e Piracicaba (MORAIS, 2010).

De acordo com Carmona et al. (2004), essa bacia apresenta vegetação nativa e recursos naturais em abundância como minerais não metálicos, areia, argila 
refratária e calcário, caracterizando-se como uma área de grande interesse ambiental, agrícola e industrial. Atualmente, um fator preocupante reside no fato dos pontos de captação de água para o abastecimento urbano encontrarem-se sob a interferência de áreas agrícolas, urbanas e industriais, como a do município de Rio Claro. Os estudos de Morais (2010) confirmam que a qualidade das águas da bacia do rio Corumbataí vem sofrendo alterações significativas devido ao mal-uso das terras pelas atividades agropecuárias e lançamento de efluentes domésticos e industriais.

De acordo com Medeiros (2012), nessa região destacam-se duas estações bem definidas: uma seca, no período de Abril a Setembro, com precipitações entre 150 e $200 \mathrm{~mm}$ e uma chuvosa, no período de Outubro a Março, com precipitações entre 1000 e 1200 mm. Segundo a classificação Koeppen, o clima é classificado como Cwa (subtropical úmido), sendo caracterizado por seca no inverno e temperatura média do mês mais quente acima de $22^{\circ} \mathrm{C}$ (CARDOSO-LEITE, 2004).

Os corpos hídricos presentes na área de estudo são os rios Corumbataí e Ribeirão Claro, destinados para captação e abastecimento de água do município de Rio Claro. De acordo com o Decreto Estadual 10.755/77, ambos os rios foram enquadrados na classe 2 (exceto um trecho do Ribeirão Claro que inclui um ponto de amostragem - ponto 4, que foi enquadrado na classe 3). A classificação dos corpos d'águas é determinada pela Resolução CONAMA 357/2005. Apesar das alterações no uso e ocupação do solo, nas atividades produtivas e na infraestrutura de saneamento, que possivelmente afetaram positiva ou negativamente a padrão de qualidade de água desses cursos d'águas, o decreto estadual é vigente, não houve atualização legal sobre esses trechos (FUNDAÇÃO AGÊNCIA DAS BACIAS PCJ, 2020).

O Rio Corumbataí nasce no município de Analândia a $1058 \mathrm{~m}$ de altitude, desembocando, após percorrer aproximadamente $110 \mathrm{~km}$, no Rio Piracicaba, no município de Piracicaba, a $470 \mathrm{~m}$ de altitude (VALENTE, 2001). A vazão média mensal desse rio é de $26 \mathrm{~m}^{3} / \mathrm{s}$ e a vazão mínima mensal é de $6 \mathrm{~m}^{3} / \mathrm{s}$ (CONCEIÇÃO; BONOTTO, 2002). De acordo com Palma-Silva (2006), os principais impactos que esse rio recebe são: a mineração, a disposição desordenada de rejeitos e a degradação da paisagem no alto curso; a carga orgânica recebida principalmente do município de Rio Claro no médio curso; e a monocultura da cana-de-açúcar e as agroindústrias no baixo curso. 
O Ribeirão Claro possui 34,04 km de comprimento, percorrendo os municípios de Corumbataí, Rio Claro, Araras e Santa Gertrudes (FONSECA, 2008). Ele nasce na zona rural do município de Corumbataí, atravessando áreas com cultivo de cana-deaçúcar e pastagens, até chegar ao perímetro urbano de Rio Claro, onde percorre a Floresta Estadual Edmundo Navarro de Andrade (FEENA), tendo sua foz no rio Corumbataí (MALAGUTTI; TAUK-TORNISIELO 2014). Este corpo d'água possui alguns pontos de captação no município de Rio Claro, sendo represado para o fornecimento de água.

Segundo dados do Departamento Autônomo de Água e Esgoto (DAAE), o município de Rio Claro possui duas captações de água superficiais, duas captações de água subterrânea, três estações elevatórias, 55 reservatórios, duas estações de tratamento de água (ETA I e ETA II), aproximadamente $915 \mathrm{~km}$ de redes de distribuição e 78.736 ligações de água (DAAE, 2019).

No que se refere ao sistema de tratamento do esgoto sanitário, de acordo com dados atuais da concessionária responsável pela coleta e tratamento dos esgotos , o município possui tratamento para $92 \%$ do esgoto coletado da área urbana e estrutura de mais de $740 \mathrm{~km}$ de redes de esgoto. Também conta com 13 estações elevatórias de esgoto e oito ETE's, sendo quatro delas localizadas em área urbana: 1) ETE Flores, em que o esgoto é tratado com reator anaeróbio (tipo UASB - Upflow Anaerobic Sludge Blanket) e, em seguida, com lodos ativados para que o efluente tratado seja lançado no rio Corumbataí; 2) ETE Palmeiras, utiliza em seu processo de tratamento, o reator UASB seguido de lagoas de aeração e decantação, com lançamento do efluente tratado também no rio Corumbataí; 3) ETE Conduta trata o esgoto com reator UASB, seguido de lodos ativados e desinfecção por ultravioleta (UV). O Ribeirão Claro é o destino de lançamento do efluente tratado; e 4) ETE Jardim Novo, que utiliza para o processo de tratamento a tecnologia NEREDA (processo de biomassa aeróbica granular) (BRK AMBIENTAL, 2019).

\section{2 Águas Superficiais e Sistema de Tratamento do Esgoto Sanitário}

Para a análise dos parâmetros de qualidade das águas superficiais utilizou-se o relatório de Qualidade das Águas Superficiais no Estado de São Paulo, elaborado pela CETESB, a partir do qual foram selecionados e compilados em tabelas os dados referentes ao Município de Rio Claro (SP). Os dados selecionados são referentes ao 
período de cinco anos de 2013 a 2017 e do ano de 2018 dos parâmetros: nitrato, nitrogênio amoniacal, fósforo total, oxigênio dissolvido (OD), demanda bioquímica de oxigênio (DBO), turbidez, condutividade elétrica, Escherichia coli e clorofila a, além de dados do Índice de Qualidade das Águas (IQA), Índice de Qualidade da Água para fins de Abastecimento Público (IAP) e Índice de Estado Trófico (IET).

Avaliou-se também as porcentagens de desconformidades com os padrões de qualidade das águas da legislação dos parâmetros: alumínio dissolvido, ferro dissolvido, cobre dissolvido, manganês total, níquel total, zinco total, cádmio total, mercúrio total, chumbo total e toxicidade crônica. Os dados foram coletados em cinco pontos de amostragem selecionados pela CETESB, descritos na Tabela 1. Esses pontos estão ordenados ao longo dos rios Corumbataí e Ribeirão Claro e destaca-se que dois deles (pontos 1 e 4) estão localizados em áreas de coleta de água para abastecimento público.

Foram consultadas a legislação CONAMA 357/2005 e a Decisão de Diretoria № 112/2013/E de 09 de abril de 2013 (CETESB, 2013) (decreto com valores norteadores do parâmetro E. coli) para análise dos dados, considerando os corpos d'água analisados de classe 2. Para uma avaliação temporal da qualidade das águas superficiais do município, foi realizada uma comparação entre os dados do presente estudo (2013-2018) e os dados obtidos por Scarlatti et al. (2019) entre os anos de 2010-2015.

Tabela 1 - Descrição dos pontos de amostragem das redes de monitoramento

\begin{tabular}{|c|c|c|c|c|c|}
\hline Corpo Hídrico & Ponto & Código CETESB & Localização do Ponto & Latitude S & Longitude W \\
\hline \multirow{3}{*}{$\begin{array}{c}\text { Rio } \\
\text { Corumbataí }\end{array}$} & $1^{*}$ & CRUM 02080 & Captação da ETA II & $22^{\circ} 19^{\prime} 29^{\prime \prime}$ & $47^{\circ} 33^{\prime} 32^{\prime \prime}$ \\
\hline & 2 & CRUM 02100 & $\begin{array}{c}\text { Ponte na Rodovia São } \\
\text { Pedro/Araras, próximo ao } \\
\text { Distrito industrial de Rio } \\
\text { Claro }\end{array}$ & $22^{\circ} 20^{\prime} 49^{\prime \prime}$ & $47^{\circ} 34^{\prime} 12^{\prime \prime}$ \\
\hline & 3 & CRUM 02200 & $\begin{array}{c}\text { Ponte na Estrada } \\
\text { Assistência/Paraisolândia, } \\
\text { em Rio Claro }\end{array}$ & $22^{\circ} 30^{\prime} 54^{\prime \prime}$ & $47^{\circ} 37^{\prime} 26^{\prime \prime}$ \\
\hline \multirow{2}{*}{$\begin{array}{l}\text { Rio Ribeirão } \\
\text { Claro }\end{array}$} & $4^{*}$ & LARO 02500 & $\begin{array}{l}\text { Captação da ETA I, } \\
\text { próximo ao Horto } \\
\text { Florestal }\end{array}$ & $22^{\circ} 24^{\prime} 33^{\prime \prime}$ & $47^{\circ} 32^{\prime} 25^{\prime \prime}$ \\
\hline & 5 & LARO 02900 & $\begin{array}{l}\text { Ponte próxima à foz do Rio } \\
\text { Claro com o Rio } \\
\text { Corumbataí, no distrito de } \\
\text { Assistência }\end{array}$ & $22^{\circ} 28^{\prime} 46^{\prime \prime}$ & $47^{\circ} 35^{\prime} 11^{\prime \prime}$ \\
\hline
\end{tabular}

* Pontos de coleta de água para abastecimento público.

Fonte: Elaborado pela autora a partir de dados da CETESB (2019) 
Para a análise da qualidade do sistema de tratamento de esgoto do município foram realizados comparações elaboradas com dados referentes à duas Estações de Tratamento de Esgoto, ETE Flores e ETE Conduta.. Os dados são referentes aos parâmetros de vazão, DBO, DQO, pH e sólidos sedimentáveis dos anos de 2017 e 2018.

A partir dessa análise, foram realizados cálculos das eficiências de remoção de $\mathrm{DBO}$ e DQO e das relações $\mathrm{DQO} / \mathrm{DBO}$. Além disso, foram feitas comparações com a legislação CONAMA 430/2011 e o Decreto Estadual 8468 de 1976, o qual estabelece diretrizes tanto para lançamento direto ou indireto de efluentes no corpo receptor, que por ventura, não foram descritas na Resolução CONAMA 430.

\section{RESULTADOS E DISCUSSÃO}

\section{1 Águas Superficiais}

A Tabela 2 apresenta os valores médios dos parâmetros de qualidade da água dos rios Corumbataí e Ribeirão Claro. Os dados são referentes a média histórica d período entre 2013 a 2017 e o primeiro ano da próxima média histórica (2018-2022), para os pontos de amostragem selecionados pela CETESB.

A condutividade elétrica é uma medida indireta da concentração de poluentes, a qual é relacionada à presença de íons dissolvidos. Apesar de a legislação não definir um valor para esse parâmetro, segundo a CETESB (2016) níveis superiores a 100 $\mu \mathrm{S} / \mathrm{cm}$ geralmente sinalizam ambientes impactados. De acordo com a Figura 1, esse valor de referência é ultrapassado nos pontos 3 e 5, indicando o aumento da concentração de íons dissolvidos à jusante da área urbana de Rio Claro.. Scarlatti et al. (2019), que analisou dados dos mesmos pontos para o ano de 2010 a 2014, obteve resultados semelhantes e, portanto, pode-se perceber que ao longo do tempo a condutividade elétrica continuou superior ao nível indicado pela CETESB nos pontos 3 e 5 . No ano de 2018, a condutividade no ponto 5 foi 1,5 vezes maior que durantes os anos de 2013 a 2017 e quase cinco vezes maior que o valor de referência indicado pela CETESB. 
Tabela 2 - Valores médios dos parâmetros de qualidade da água dos rios Corumbataí e Ribeirão Claro

\begin{tabular}{|c|c|c|c|c|c|c|c|c|c|c|}
\hline \multirow{4}{*}{ Parâmetros } & \multicolumn{10}{|c|}{ Pontos de Amostragem } \\
\hline & \multicolumn{6}{|c|}{ Rio Corumbataí } & \multicolumn{4}{|c|}{ Rio Ribeirão Claro } \\
\hline & \multicolumn{2}{|c|}{$1^{*}$} & \multicolumn{2}{|c|}{2} & \multicolumn{2}{|r|}{3} & \multicolumn{2}{|r|}{$4^{\star}$} & \multicolumn{2}{|c|}{5} \\
\hline & 2018 & 2013/2017 & 2018 & $2013 / 2017$ & 2018 & 2013/2017 & 2018 & 2013/2017 & 2018 & 2013/2017 \\
\hline Condutividade Elétrica $(\mu \mathrm{S} / \mathrm{cm})$ & 58 & 48 & 59 & 48 & 195 & 218 & 65 & 60 & 448 & 301 \\
\hline Turbidez (UNT) & 64 & 72 & 68 & 72 & 56 & 87 & 16 & 30 & 20 & 74 \\
\hline Nitrato (mg/L) & 0,94 & 0,82 & 0,95 & 0,83 & 1,7 & 0,82 & 0,47 & 0,38 & 3,4 & 2,1 \\
\hline Nitrogênio Amoniacal (mg/L) & 0,5 & 0,32 & 0,5 & 0,29 & 1,3 & 2 & 0,5 & 0,34 & 1,8 & 2 \\
\hline $\begin{array}{l}\text { Oxigênio Dissolvido } \\
\text { (mg/L) }\end{array}$ & 7,6 & 7,4 & 7,9 & 7,7 & 6,7 & 5,5 & 7,3 & 6,4 & 7,3 & 7,1 \\
\hline $\mathrm{DBO}(\mathrm{mg} / \mathrm{L})$ & 2,3 & 2,3 & 2,3 & 2,3 & 5,2 & 5,6 & 2 & 2,2 & 3,5 & 5,1 \\
\hline Fósforo (mg/L) & 0,095 & 0,074 & 0,09 & 0,069 & 0,35 & 0,33 & 0,038 & 0,033 & 0,62 & 0,42 \\
\hline Escherichia coli (UFC/100mL) & 1712 & 3239 & 1261 & 2570 & 5749 & 33700 & 213 & 575 & 635 & 1830 \\
\hline Clorofila a $(\mu \mathrm{g} / \mathrm{L})$ & 1,6 & 2,9 & 1,4 & 2 & 1,5 & 2,7 & 1 & 0,95 & 3,8 & 5,4 \\
\hline Faixa de $\mathrm{pH}$ & $6,6-7,1$ & & $6,6-7,3$ & & $6,8-7,7$ & & $6,8-7,3$ & & $6,9-7,3$ & \\
\hline
\end{tabular}

* Pontos de coleta de água para abastecimento público.

Fonte: Elaborada pelos autores a partir de dados da CETESB (2019) 
Figura 1 - Resultados comparativos entre os pontos de amostragem referente ao parâmetro Condutividade Elétrica

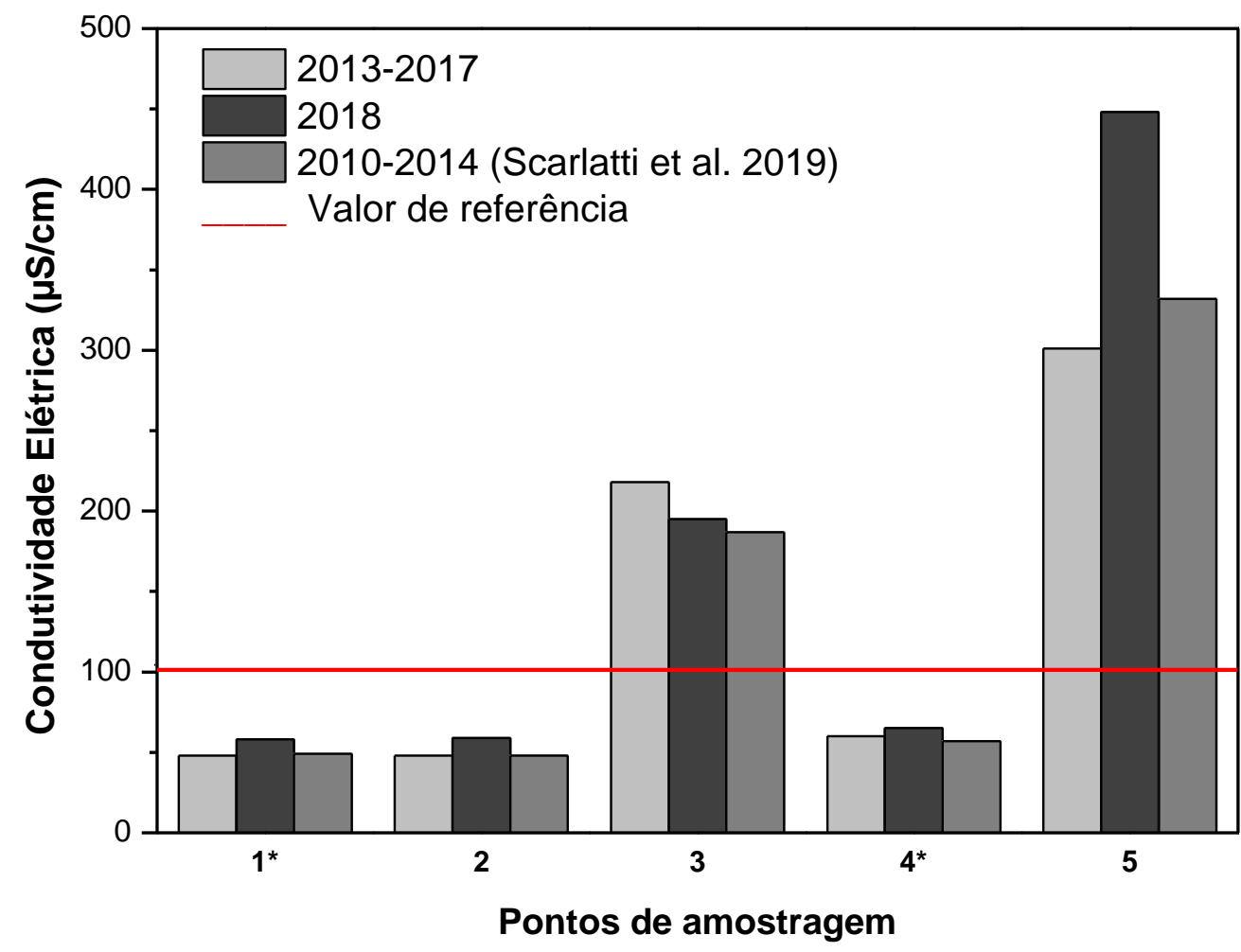

O oxigênio dissolvido $(\mathrm{OD})$ é de fundamental importância para avaliar as condições naturais da água e detectar impactos ambientais, como eutrofização e poluição orgânica (PALMA-SILVA, 2006). A Resolução CONAMA 357/2005, classe 2, estabelece como limite mínimo o valor de $5 \mathrm{mg} / \mathrm{L}$ de OD e nenhum dos pontos obteve um valor abaixo dessa condição. Já a Demanda Bioquímica de Oxigênio (DBO) é a quantidade de oxigênio necessária para oxidar a matéria orgânica por decomposição microbiana num determinado período de tempo (CETESB, 2016). A legislação vigente estabelece como padrão o limite máximo de $5 \mathrm{mg} / \mathrm{L}$ e, para os períodos de 2010-2014 e 2013-2017, os pontos 3 e 5 estão acima dessa condição (Figura 2). Em 2018, porém, houve uma redução na concentração de DBO, praticamente enquadrando todos os trechos analisados. Contudo, pode-se notar o aumento das concentrações de DBO nos pontos que são localizados à jusante da área urbana. Realizando-se balanços de massas simplificados (dados não mostrados), antecipa-se que esses aumentos são decorrentes de lançamentos irregulares e clandestinos, não sendo as ETEs as responsáveis por esse aumento de DBO a partir do lançamento dos esgotos tratados. 
Figura 2 - Gráfico comparativo entre os pontos de amostragem, a Resolução CONAMA 357/2005 e o trabalho de Scarlatti et al. (2019) para o parâmetro Demanda Bioquímica de Oxigênio (DBO)

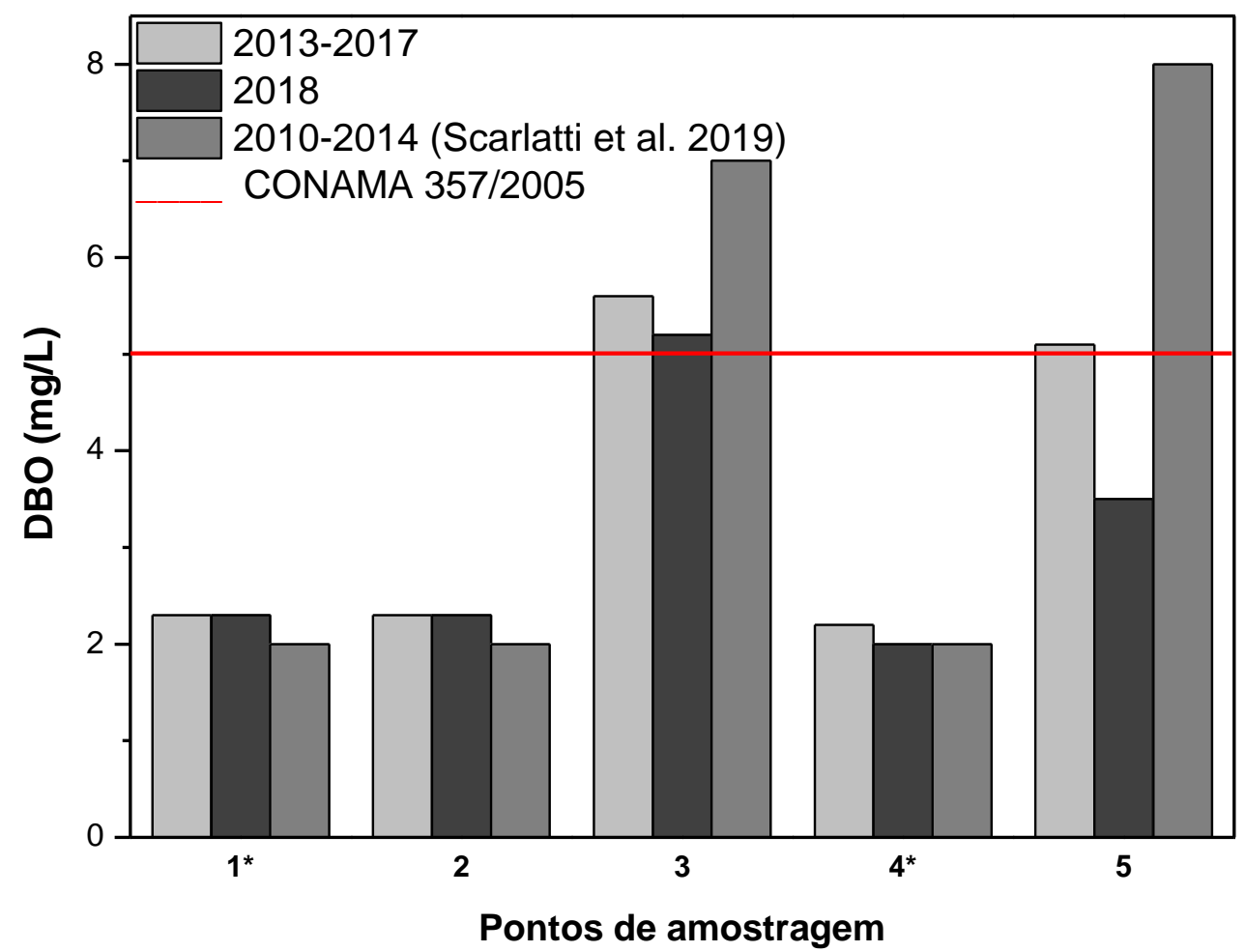

Com relação ao parâmetro associado a patógenos, o limite permitido em águas doces de classe 2 é de 1000 UFC/100 mL para coliformes termotolerantes, , conforme estabelecido pela Resolução CONAMA no 357/2005. Entretanto, a Decisão de Diretoria 112/2013/E, estabelecida pela CETESB determina o limite máximo de 600 UFC/100mL para Escherichia coli. De acordo com a Figura 3, exceto o ponto 4, no ano de 2018, todos os outros pontos ultrapassaram essa condição, o que indica a contaminação fecal dessas águas. Não se pode afirmar com certeza se essa contaminação é de origem humana ou animal, mas, por serem concentrações elevadas, é possível que haja uma contribuição combinada de vários fatores, como o lançamento de efluentes domésticos e agropecuários, irregulares e clandestinos. Em especial, a concentração do ponto 3 é relativa e significativamente maior do que os outros pontos, cujo cenário causa preocupação. Contudo, as concentrações foram menores para o ano de 2018 do que os períodos anteriores, assim como ocorreu para o parâmetro DBO. 
Figura 3 - Gráfico comparativo entre os pontos de amostragem, a Decisão de Diretoria 112/2013/E e o trabalho de Scarlatti et al. (2019) para o parâmetro Escherichia coli

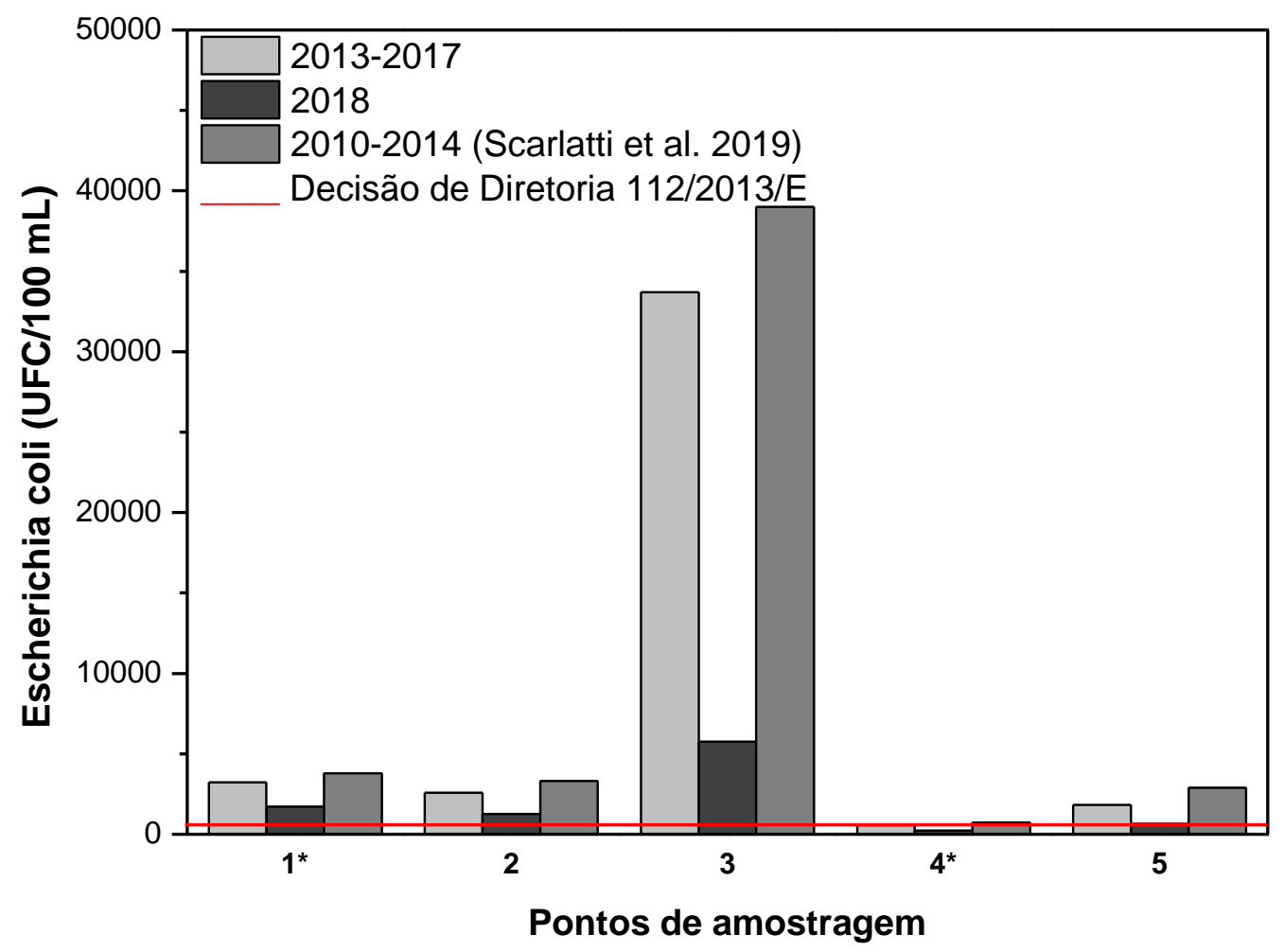

O fósforo não é normalmente encontrado em concentrações significativas nas águas superficiais por ser ativamente absorvido pelas plantas, porém sua concentração pode ser aumentada devido a despejos orgânicos e/ou industriais e essas concentrações, quando muito elevadas, levam à ocorrência da eutrofização, acarretando no desenvolvimento de algas (MORAIS, 2010). De acordo com a Resolução CONAMA 357/2005, o limite máximo de fósforo total em ambientes lóticos é de $0,1 \mathrm{mg} / \mathrm{L}$ e constatou-se que nos pontos 3 e 5 o limite foi ultrapassado, em ambos os períodos de tempo avaliados. Falqueto (2008) apontou que o motivo dessa elevada concentração pode ser a lixiviação de fertilizantes utilizados nas plantações de cana de açúcar nesta região. Também pode ser ocasionada pelo lançamento de efluentes industriais ou domésticos, como se constatou observando os números elevados de $E$. coli que foram encontrados.

A turbidez é indicada pelo grau de interferência na passagem da luz na água, ocasionada pelas partículas suspensas nesta, impactando processos como o de fotossíntese aquática e conferindo uma aparência turva na água (PALMA-SILVA, 2006). A Resolução CONAMA 357/2005 estabelece como limite o valor de 100 UNT, e nenhum ponto de amostragem excedeu essa condição. 
A clorofila a é considerada o principal parâmetro que indica o estado trófico dos corpos d'água (CETESB, 2016). A Resolução CONAMA 357/2005 estabelece como limite máximo o valor de $30 \mu \mathrm{g} / \mathrm{L}$ e todos os pontos atenderam a esse padrão.

A legislação estabelece como padrão para o nitrato o limite de $10 \mathrm{mg} / \mathrm{L}$ e os resultados obtidos não ultrapassaram esse limite. Com relação ao nitrogênio amoniacal, os limites máximos são determinados pela legislação de acordo com os valores de $\mathrm{pH}$. Para valores menores ou iguais a 7,5, caso dos pontos 1, 2, 4 e 5, o limite máximo de nitrogênio amoniacal é de $3,7 \mathrm{mg} / \mathrm{L}$, o que foi cumprido. Já para valores de pH entre 7,5 e 8,0, caso do ponto 3 , a concentração máxima de nitrogênio permitida é de $2,0 \mathrm{mg} / \mathrm{L}$, o que também foi cumprido.

$\mathrm{Na}$ Figura 4 estão apresentados os valores médios das concentrações dos metais alumínio ( $\mathrm{Al}$ ) e ferro $(\mathrm{Fe})$ na fração dissolvida para o ano de 2018 e o limite máximo permitido pela Resolução CONAMA 357/2005 para águas classe 2.

Figura 4 - Concentrações médias dos metais alumínio e ferro para o ano de 2018
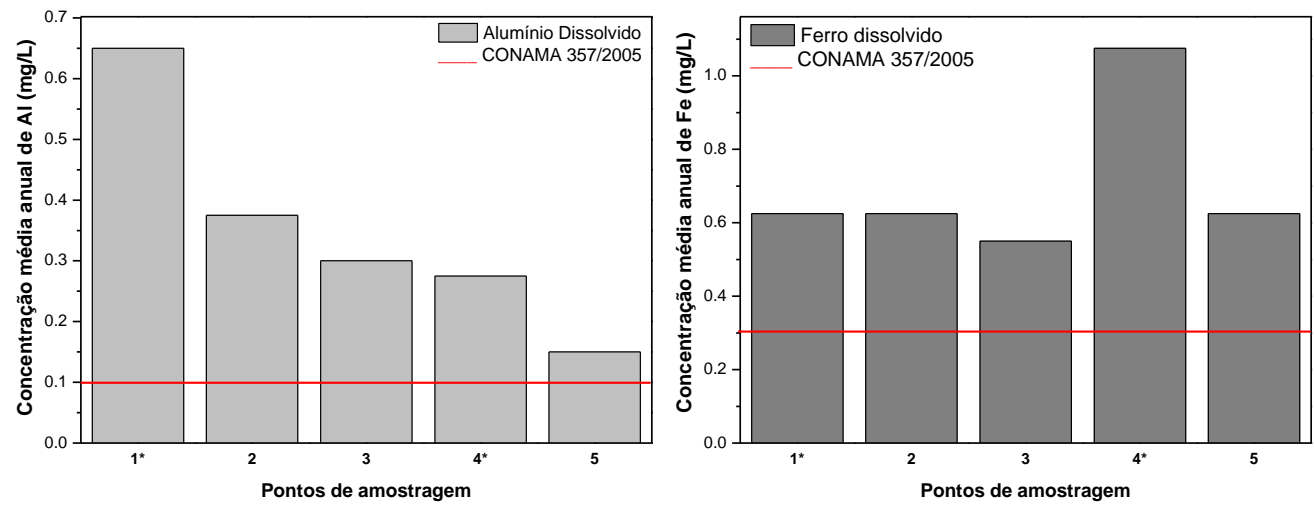

Distintivamente ao padrão observado para os parâmetros anteriores, as concentrações de alumínio dissolvido e ferro dissolvido foram maiores para os pontos (1, 2 e 4) à montante em comparação aos pontos à jusante (3 e 5). Dessa maneira, é demonstrado que o lançamento de efluentes tratados ou brutos não é causa pela ultrapassagem dos limites estabelecidos pela legislação. Possivelmente, as concentrações desconformes desses metais são originadas pela degradação do solo, atividades mineradoras, escoamento superficial e lixiviação. Os metais cobre, manganês, níquel, zinco, cádmio, mercúrio e chumbo tiveram concentrações desprezíveis. 


\section{2 Índices para Avaliação da Qualidade da Água}

O Índice de Qualidade das Águas (IQA) foi desenvolvido para analisar as condições de qualidade da água das águas superficiais, levando em conta nove variáveis consideradas relevantes para tal avaliação $(\mathrm{OD}, \mathrm{DBO}$, coliformes totais e termotolerantes, nitrogênio total, fósforo total, sólidos totais, $\mathrm{pH}$, turbidez e temperatura) (ANA, 2019). A partir do cálculo do produtório ponderado dos parâmetros citados, é indicado um índice IQA, variando numa escala de 0 a 100 e assim categorizando a água como: classificação ÒTIMA, $79<I Q A \leq 100$; classificação BOA, 51 < IQA $\leq 79$; classificação REGULAR, 36 < IQA $\leq 51$; classificação RUIM, 19 < IQA $\leq 36$ e classificação PÉSSIMA com IQA $\leq 19$.

O Índice de Qualidade da Água para fins de Abastecimento Público (IAP) é um índice mais fidedigno e tem como objetivo indicar as condições de qualidade das águas para fins de abastecimento público e, devido a isso, é calculado somente em pontos de transposição das águas para outros reservatórios ou pontos correspondentes com as captações para abastecimento público com classificações categorizadas da mesma forma que o IQA(CETESB, 2019).

O Índice de Estado Trófico (IET) é calculado pela CETESB, baseando-se nos parâmetros clorofila a e fósforo total e tem como objetivo caracterizar os corpos d'água em diferentes graus de trofia, ou seja, verifica a qualidade da água de acordo com os nutrientes e seu efeito no crescimento excessivo de algas e cianobactérias (CETESB, 2019). O IET é indicado por classe de trofia de acordo com as faixas de valores apresentadas a seguir: classificação ULTRAOLIGOTRÓFICO com valores $\leq 47$; classificação OLIGOTRÓFICO, 47 < IET $\leq 52$; classificação MESOTRÓFICO, 52 < IET $\leq 59$; classificação EUTRÓFICO, 59 < IET $\leq$ 63; classificação SUPEREUTRÓFICO, 63 < IET $\leq 67$ e, classificação HIPEREUTRÓFICO, com IET > 67.

A Tabela 3 traz os resultados obtidos pela CETESB, para o ano de 2018, dos principais indicadores de qualidade das águas: Índice de Qualidade das Águas (IQA), Índice de Qualidade da Água para fins de Abastecimento Público (IAP) e Índice de Estado Trófico (IET). 
Tabela 3 - Resultado dos Indicadores de Qualidade das Águas (2018)

\begin{tabular}{ccccccccc}
\hline Indicadores & Pontos & Janeiro & Março & Maio & Julho & Setembro & Novembro & Média 2018 \\
\hline \multirow{5}{*}{ IQA } & $1^{*}$ & 57 & 46 & 69 & 71 & 71 & 63 & 63 \\
& 2 & 56 & 46 & 72 & 76 & 72 & 63 & 64 \\
& 3 & 41 & 52 & 56 & 55 & 54 & 43 & 50 \\
& $4^{*}$ & 69 & 73 & 76 & 80 & 76 & 71 & 74 \\
\hline \multirow{2}{*}{ IAP } & 5 & 58 & 67 & 64 & 50 & 50 & 57 & 58 \\
\hline \multirow{6}{*}{ IET } & $1^{*}$ & 10 & - & 63 & 67 & - & 36 & 44 \\
& $4^{*}$ & 45 & - & 75 & 78 & - & 11 & 52 \\
\hline $1^{*}$ & 54 & - & 52 & 53 & - & 59 & 54 \\
& 2 & 54 & - & 53 & 52 & - & 58 & 54 \\
& 3 & 59 & - & 59 & 60 & - & 57 & 59 \\
& $4^{*}$ & 54 & - & 50 & 50 & - & 52 & 51 \\
& 5 & 60 & - & 63 & 67 & - & 66 & 64 \\
\hline
\end{tabular}

*Pontos de coleta de água para abastecimento público.

Fonte: Elaborada pelos autores a partir de dados da CETESB (2019)

Segundo o índice IQA que avalia a qualidade das águas superficiais, os pontos 1, 2, 4 e 5 obtiveram a classificação considerada BOA, enquanto que o ponto 3 obteve a classificação REGULAR. Essa classificação regular corrobora os piores resultados dos parâmetros de qualidade de água apresentados acima (por exemplo, menor valor de $\mathrm{OD}$ e maiores valores de $\mathrm{DBO}$ e E. Coli.), relativos ao ponto que se encontra à jusante da bacia, após sofrer a interferência de atividades domésticas, industriais e rurais do município.

Para águas de abastecimento público, são levados em conta o índice IAP e, portanto, para o ponto 1, próximo à captação da ETA II, obteve-se a classificação REGULAR. Porém, vê-se que houve uma variação entre PÉSSIMA (janeiro), BOA (maio e julho) e RUIM (novembro). Já no ponto 4, próximo à captação da ETA I, a classificação obtida foi BOA, mas também pode-se perceber que ocorreu uma variação entre REGULAR (janeiro), BOA (maio e julho) e PÉSSIMA (novembro).

Com base nos índices IQA e IAP, observa-se que as piores classificações foram encontradas nos períodos mais chuvosos do ano, de outubro a março, enquanto que as melhores classificações ocorreram nos meses de seca, de abril a setembro. Fazendo uma análise temporal, Scarlatti et al. (2019) também encontrou que a qualidade das águas diminuiu no período de chuvas. Uma explicação para essa conclusão é que em períodos chuvosos o escoamento superficial é maior, o que acarreta no transporte de uma maior quantidade de sedimentos, sólidos suspensos, nutrientes, entre outras substâncias. Por serem pontos presentes em locais de 
captação de água para abastecimento público, é necessário que as estações realizem um tratamento mais robusto, principalmente nos períodos chuvosos.

Segundo a CETESB (2016), devido ao carreamento de solos e processos de erosão que ocorrem nas margens dos corpos d'água, as concentrações de alumínio e ferro, cujos teores são abundantes em solos dessa região, podem aumentar em períodos chuvosos. Nos meses de janeiro e novembro do ano de 2018, foram observadas as maiores concentrações de ambos os metais alumínio e ferro (Figura $5)$.

Figura 5 - Variação temporal e espacial das concentrações de alumínio e ferro no ano de 2018
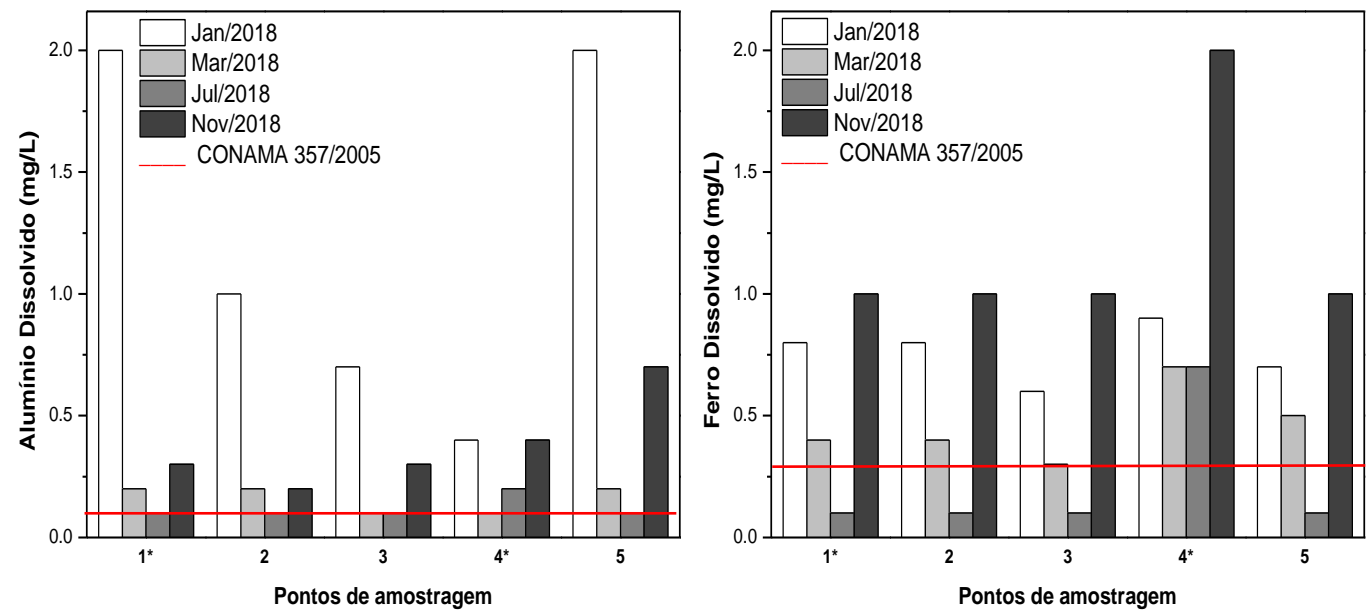

O ponto 5 foi o que apresentou maior IET, sendo classificado como SUPEREUTRÓFICO em virtude do fósforo total presente nos corpos d'água, que nesse ponto apresentou concentração 20 vezes maior do que o valor determinado pela legislação (em 2018 com valor de 0,62 mg/L, Tabela 2). Além disso, a concentração de clorofila a encontrada nesse ponto foi a maior dentre todos, mesmo que esteja dentro do padrão estabelecido pela Resolução CONAMA 357/2005. Comparando com o resultado encontrado por Scarlatti et al. (2019), onde os pontos 3 e 5 possuíam os maiores IET (ambos com 63), o ponto 5 continuou sendo o ponto com maior grau de trofia, enquanto o ponto 3 apresentou uma queda na classificação. Vale a pena lembrar que o ponto 5 sofre a influência da Floresta Estadual "Edmundo Navarro de Andrade" (FEENA), localizada no munícipio. 


\subsection{Sistema de Tratamento do Esgoto Sanitário}

A Tabela 4 apresenta os dados de vazão (L/s), DBO (mg/L), DQO (mg/L), pH e sólidos sedimentáveis ( $\mathrm{ml} / \mathrm{L})$, referentes às Estações de Tratamento Flores e Conduta, obtidos com a empresa responsável pelo saneamento do município, para os anos de 2017 e 2018.

Tabela 4 - Características físico-químicas dos afluentes e efluentes das ETE's Flores e Conduta

\section{Parâmetros}

Estação de
Tratamento Ano Vazão (L/s) DBO (mg/L) DQO (mg/L) pH $\begin{gathered}\text { Sólidos } \\ \begin{array}{c}\text { Sedimentáv } \\ \text { eis }(\mathrm{ml} / \mathrm{L})\end{array}\end{gathered}$

\begin{tabular}{ccccccccccc} 
& & & Af & Ef & Af & Ef & Af & Ef & Af & Ef \\
\hline \multirow{2}{*}{ ETE Flores } & 2017 & 85,4 & 327,8 & 12,4 & 639,6 & 54,9 & 7,3 & 7,3 & 3,5 & 0,1 \\
& 2018 & 78,3 & 315,3 & 14,1 & 657,9 & 66,3 & 7,3 & 7,4 & 5 & 0,2 \\
ETE & 2017 & 154,4 & 273 & 9,2 & 550,7 & 43,5 & 7,2 & 6,7 & 2,8 & 0,1 \\
Conduta & 2018 & 153,8 & 285,1 & 10,8 & 608 & 56,4 & 7,1 & 6,9 & 4,8 & 0,2 \\
\hline
\end{tabular}

Af - Afluente; Ef - Efluente

Fonte: Elaborada pelos autores a partir de dados da empresa de saneamento (2019)

Seguindo os limites preconizados pelas legislações citadas a seguir, a Resolução CONAMA 430/2011 estabelece como padrões para os parâmetros DBO, pH e sólidos sedimentáveis: $<120 \mathrm{mg} / \mathrm{L} \mathrm{DBO} ; 5 \mathrm{pH}<9$ e $<1 \mathrm{ml} / \mathrm{L}$ para sólidos sedimentáveis. Já o Decreto Estadual 8468/76 determina os valores: $<60 \mathrm{mg} / \mathrm{L}$ DBO, $5<\mathrm{pH}<9$ e $<1 \mathrm{ml} / \mathrm{L}$ para sólidos sedimentáveis. Para a ETE Flores, observando-se a Resolução CONAMA 430/2011 vê-se que os parâmetros DBO, pH e sólidos sedimentáveis, para os anos de 2017 e 2018, ficaram dentro dos padrões de lançamento para efluentes de sistemas de tratamento de esgotos sanitários. Com relação ao Decreto Estadual 8468/76, os parâmetros também respeitaram os padrões presentes na legislação para ambos os anos. Tanto a legislação federal quanto a estadual não abrangem o parâmetro DQO.

No ano de 2017, a eficiência de remoção de DBO foi de $95,74 \%$, enquanto a de DQO foi de $91,41 \%$. A relação DQO/DBO para o afluente foi de 1,95 e para o efluente foi 4,42 . Pode-se perceber que a relação aumentou 2,26 vezes para o efluente final, o que, de acordo com as faixas de Von Sperling (2005), indica uma elevada fração inerte (não biodegradável). Já para o ano de 2018, a eficiência de remoção de DBO foi de $95,53 \%$ e a de DQO foi $89,93 \%$. A relação DQO/DBO para o 
afluente foi de 2,086 e para o efluente foi 4,70. Pode-se perceber que a relação DQO/DBO aumentou 2,25 vezes, o que indica uma elevada fração não biodegradável (VON SPERLING, 2005).

Scarlatti et al. (2019), em seu estudo feito para o ano de 2015, também obteve como resultado a conformidade de todos os parâmetros com as legislações vigentes. A eficiência de remoção de DBO encontrada foi próxima de $88 \%$, mostrando que houve uma melhora no sistema de tratamento dessa estação entre 2015 e 2018.

Com relação à ETE Conduta, os parâmetros DBO, pH e sólidos sedimentáveis, tanto para o ano de 2017 quanto para 2018, ficaram dentro dos padrões de lançamento estabelecidos pela Resolução CONAMA 430/2011. Levando-se em consideração o Decreto Estadual 8468/76, percebe-se que os parâmetros analisados também cumpriram os padrões determinados. Ambas as legislações não incluem o parâmetro DQO.

As eficiências de remoção de DBO e DQO encontradas foram de, respectivamente, $96,64 \%$ e $92,1 \%$ para o ano de 2017 e de $96,20 \%$ e $90,72 \%$ para o ano de 2018. A relação DQO/DBO identificada para o afluente foi de 2,017 e para o efluente foi de 4,75, no que se refere ao ano de 2017. Percebe-se que houve um aumento de 2,35 vezes para essa relação, o que indica um nível elevado de fração inerte (VON SPERLING, 2005). Quanto ao ano de 2018, a relação de DQO/DBO encontrada para o afluente foi de 2,13 e para o efluente foi de 5,21. Houve um aumento de 2,45 vezes, significando uma elevada fração não biodegradável de acordo com a faixa de Von Sperling (2005).

Realizando a comparação com os resultados obtidos por Scarlatti et al. (2019), referentes ao ano de 2015, percebe-se que o desempenho dessa estação de tratamento se manteve. Todos os parâmetros analisados permaneceram em conformidade com a legislação e as eficiências de remoção de DBO ficaram constantes, acima de 95\%.

O tratamento utilizado nas ETE's Flores e Conduta (reator UASB) é um tratamento biológico e, quanto maior for a eficiência deste tratamento, maior vai ser a relação DQO/DBO. Portanto, os aumentos ocorridos nessa relação em ambas as estações, tanto em 2017 quanto em 2018, estão dentro do esperado, corroborando a eficácia do tratamento na remoção de material orgânico e indicando a presença de material remanescente correspondente às parcelas orgânica de difícil degradação e inorgânica. 


\section{CONCLUSÕES}

A variação no grau de pureza da água foi mais relacionada com o espaço, local do curso d'água, do que com o período de monitoramento. Ao longo dos cursos d'águas do Rio Corumbataí e Ribeirão Claro, foi verificada a diminuição do padrão de qualidade das águas superficiais, em relação a vários parâmetros como DBO, OD, fósforo, condutividade e Escherichia coli, nos períodos de 2010 e 2018, em decorrência da influência da área urbana, ou seja, os pontos que apresentaram os melhores valores ou índices de qualidades encontram-se à montante da bacia. Em contraste, os parâmetros de ferro dissolvido e alumínio dissolvidos tiveram as maiores concentrações e, portanto, o pior grau de qualidade nos trechos iniciais dos cursos d'águas, ou seja, antes do recebimento dos efluentes tratados (ou brutos irregulares) da área urbana. É possível que as atividades domésticas, industriais e agrícolas exerceram influência significativa no quadro dos constituintes orgânicos, microbiológicos e nutrientes, enquanto que atividades de mineração, degradação de solos e lixiviação predominaram na questão dos metais alumínio e ferro. Ao longo dos anos, os parâmetros de qualidade de águas ferro dissolvido, alumínio dissolvidos, fósforo total, DBO e Escherichia coli estiveram em desconformidade com a legislação. As fontes de poluição difusas responsáveis pelo aumento dos parâmetros ferro e alumínio dissolvidos, caso sejam naturais, possuem uma maior dificuldade de controle, porém as emissões de efluentes e atividades produtivas são fontes que poderiam ter um grau maior de fiscalização. Mais estudos são necessários para investigar a origem e o destino de parâmetros associados a coliformes. A análise do sistema de tratamento de esgoto apresentou resultados positivos. Ambas as estações de tratamento obtiveram seus parâmetros dentro dos padrões de lançamento de efluentes estabelecidos pela legislação e as eficiências de remoção de DBO ficaram acima de $95 \%$ no ano de 2018. Portanto, é possível concluir que o método de tratamento utilizado nas duas estações avaliadas possui um bom desempenho, em relação à remoção da matéria orgânica, que é confirmada pela relação DQO/DBO. O lançamento dos esgotos tratados não acarretou o aumento de DBO (que houve) nos pontos 3 e 5 à jusante da área urbana. 


\section{AGRADECIMENTOS}

Os autores agradecem ao Conselho Nacional de Desenvolvimento Científico e Tecnológico (CNPq) pelo apoio e suportes financeiros concedidos.

\section{REFERÊNCIAS}

AGÊNCIA NACIONAL DE ÁGUAS. Panorama das águas superficiais do Brasil: indicadores de qualidade. Disponível em: https://www.ana.gov.br/panorama-dasaguas/qualidade-da-agua/indicadores-de-qualidade. Acesso em: 28 mar. 2019.

BRASIL. Lei no 11445, de 05 de janeiro de 2007. Brasília, 2007. Estabelece as diretrizes nacionais para o saneamento básico. Disponível em: http://www.planalto.gov.br/ccivil_03/_Ato2007-2010/2007/Lei/L11445.htm. Acesso em: 28 mar. 2019.

BRASIL. Ministério do Desenvolvimento Regional. Secretaria Nacional de Saneamento Ambiental - SNSA. Sistema Nacional de Informações sobre Saneamento: diagnóstico dos serviços de água e esgotos - 2018. Disponível em: http://www.snis.gov.br/diagnosticoagua-e-esgotos. Acesso em: 29 abr. 2020.

BRASIL. Ministério do Desenvolvimento Regional. Secretaria Nacional de Saneamento Ambiental - SNSA. Sistema Nacional de Informações sobre Saneamento: série histórica 2018. Disponível em: http://app4.mdr.gov.br/serieHistorica/\#. Acesso em: 29 abr. 2020.

BRASIL. Ministério do Meio Ambiente. Conselho Nacional do Meio Ambiente. Resolução no 357, de 17 de março de 2005. Dispõe sobre a classificação dos corpos de água e diretrizes ambientais para o seu enquadramento, bem como estabelece as condições e padrões de lançamento de efluentes, e dá outras providências. Disponível em:

http://pnqa.ana.gov.br/Publicacao/RESOLUCAO_CONAMA_n_357.pdf. Acesso em: 28 mar. 2019.

BRASIL. Ministério do Meio Ambiente. Conselho Nacional do Meio Ambiente. Resolução no 430, de 13 de maio de 2011. Dispõe sobre as condições e padrões de lançamento de efluentes, complementa e altera a Resolução no 357, de 17 de março de 2005, do Conselho Nacional do Meio Ambiente-CONAMA. Disponível em:

http://www2.mma.gov.br/port/conama/legiabre.cfm?codlegi=646. Acesso em: 28 mar. 2019.

BRK Ambiental. Disponível em: https://www.brkambiental.com.br/rio-claro. Acesso em: 28 mar. 2019.

CARDOSO-LEITE, E.; COVRE, T. B., OMETTO, R. G., CAVALCANTI, D. C., PAGANI, M. I. Fitossociologia e caracterização de mata ciliar, em Rio Claro, São Paulo, como subsídio à recuperação da área. Revista do Instituto Florestal, São Paulo, v.16, n.1, p. 31-41, 2004.

CARMONA, E. C.; FAGUNDES, P.; GIMENEZ, D. D.; JORDÃO, M. W.; JORDÃO, S. E. R.; REIS, J. C.; RIBEIRO, M. A. H. W.; SANCHEZ, M. C.; SENEDA, R. M.; SOUZA, A. M. G. de F. Diagnóstico da Água no Município de Rio Claro. Rio Claro, 2004. 110 p.

COMPANHIA AMBIENTAL DO ESTADO DE SÃO PAULO. Apêndice E: significado ambiental e sanitário das variáveis de qualidade das águas e dos sedimentos e metodologias analíticas e de amostragem. São Paulo: CETESB, 2016. 
COMPANHIA AMBIENTAL DO ESTADO DE SÃO PAULO. Apêndice J: resultados do monitoramento. São Paulo: CETESB, 2019.

COMPANHIA AMBIENTAL DO ESTADO DE SÃO PAULO. Dados do Saneamento Básico dos Municípios Paulistas. São Paulo: CETESB, 2016.

COMPANHIA AMBIENTAL DO ESTADO DE SÃO PAULO. Relatório de qualidade das águas interiores no estado de São Paulo. São Paulo: CETESB, 2019.

CONCEIÇÃO, F. T.; BONOTTO, D. M. Relações hidroquímicas aplicadas na avaliação da qualidade da água e diagnóstico ambiental na bacia do Rio Corumbataí (SP). Geochimica Brasiliensis, v. 16, n. 1, p. 1, 2002.

DAAE - Departamento Autônomo de Água e Esgoto. Disponível em:

http://www.daaerioclaro.sp.gov.br/index.php. Acesso em: 29 mar. 2019.

FALQUETO, M. A. Avaliação do índice de qualidade da água (IQA) e dos elementos químicos nas águas e nos sedimentos do rio Corumbataí, SP. 2008. 117 p. Dissertação (Mestrado) - Universidade de São Paulo, Escola Superior de Agricultura "Luiz de Queiroz", Piracicaba, 2008.

FONSECA, W. C. Ajuste do modelo QUAL2K e simulação de cenários para o Ribeirão Claro. 2008. 55 f. Trabalho de conclusão de curso (Engenharia Ambiental) - Universidade Estadual Paulista, Instituto de Geociências e Ciências Exatas, 2008.

FUNDAĈ̃O AGÊNCIA DAS BACIAS PCJ. Estudo do uso dos recursos hídricos na Bacia Hidrográfica do Rio Corumbataí visando estabelecer cenários e planejamento das alternativas de abastecimento de água para os municípios pertencentes a esta bacia. Relatório Final. Piracicaba, 2020. Disponível em:

http://www.agencia.baciaspcj.org.br/docs/gestao/contrato-48-2018-estudo-v1-t2.pdf. Acesso em: 30 set. 2020.

IBGE - Instituto Brasileiro de Geografia e Estatística. Ministério do Planejamento, Orçamento e Gestão, Brasília: IBGE, 2018. Disponível em: https://cidades.ibge.gov.br/brasil/sp/rioclaro/panorama. Acesso em: 28 mar. 2019.

MALAGUTTI, E. N; TAUK-TORNISIELO, S. M. Qualidade das águas do córrego bandeirantes na sub-bacia do ribeirão claro, município de Rio Claro, SP, Brasil. Holos Environment, v. 14, n. 2, p. 135-152, 2014. https://doi.org/10.14295/holos.v14i2.9270

MARANHO, L. A. Avaliação da qualidade da água do rio Corumbataí (SP) por meio de variáveis bióticas e abióticas. 2012. 107 p. Tese (Doutorado) - Universidade de São Paulo, Piracicaba, 2012.

MEDEIROS, C. B. Avaliação da vulnerabilidade à contaminação das águas subterrâneas do Aquífero Rio Claro Na Mineração Mandu, Distrito De Ajapi, Rio Claro SP. 2012. 68 p. Trabalho de Conclusão de Curso (Graduação em Geologia) -Instituto de Geociências e Ciências Exatas, Universidade Estadual Paulista, Rio Claro, 2012.

MORAIS, E. B. Indicadores microbiológicos, metais e índice de qualidade da água (IQA) associados ao uso e ocupação da terra para avaliação da qualidade ambiental da microbacia do rio cabeça, na bacia do rio Corumbataí, SP. 2010. 158 p. Tese (Doutorado) - Universidade Estadual Paulista, Instituto de Biociências, Rio Claro, 2010.

MOTA, S. Gestão ambiental de recursos hídricos. 3. ed. Rio de Janeiro: ABES. 2008. 344 p. 
PALMA-SILVA, G. M. D. Relação dos indicadores microbiológicos com outros parâmetros limnológicos no rio Corumbataí, SP, no intuito de propor um modelo matemático para gestão ambiental. Rio Claro, 175 p., 2006. Tese (Doutorado em Ciências Biológicas) - Universidade Estadual Paulista, Instituto de Biociências de Rio Claro.

PLANO NACIONAL DE RECURSOS HÍDRICOS. Águas para o futuro - cenários para 2020. Volume 2. Ministério do Meio Ambiente, Secretaria de Recursos Hídricos. Brasília: MMA, 2006.

SÃO PAULO. Decisão de diretoria no 112/2013/E, de 09 de abril de 2013. São Paulo: CETESB, 2013.

SÃO PAULO. Decreto no $\mathbf{8 4 6 8}$, de 8 de setembro de 1976. Aprova o Regulamento da Lei no 997, de 31 de maio de 1976, que dispõe sobre a prevenção e o controle da poluição do meio ambiente.

SCARLATTI, V. M; QUELUZ, J. G. T.; YABUKI, L. N. M.; GARCIA, M. L. Avaliação da qualidade das águas superficiais do município de Rio Claro/SP. Revista Geociências UNESP, v. 38, n. 3, p. 741-754, 2019. https://doi.org/10.5016/geociencias.v38i3.13798

SIGRH - Sistema Integrado de Gerenciamento de Recursos Hídricos do Estado de São Paulo. Disponível em: http://www.sigrh.sp.gov.br/main. Acesso em: 28 mar. 2019.

VALENTE, O. A. \& VETTORAZZI, C. A. Avaliação da estrutura florestal na bacia hidrográfica do Rio Corumbataí, SP. Scientia Forestalis, Piracicaba, n. 68, p. 45-57, 2005.

VALENTE, R. A. Análise da estrutura da paisagem na bacia do rio Corumbataí, SP. Piracicaba: USP, 2001.

VON SPERLING, M. Introdução à qualidade das águas e ao tratamento de esgotos: princípios do tratamento biológico de águas residuárias. Belo Horizonte: Editora UFMG, 2005.

ZAMBETTA, P. M. A. Espécies químicas inorgânicas (Al, As, Cd, Cr, Cu, $\mathrm{Fe}, \mathrm{Hg}, \mathrm{Mn}, \mathrm{Ni}$, $\mathrm{Pb}$ e $\mathrm{Sn}$ ) no sedimento e nos sólidos em suspensão do rio Corumbataí, SP. Piracicaba, 2006. Dissertação (Mestrado em Ecologia de Agroecossistemas) - Ecologia de Agroecossistemas, Universidade de São Paulo. 